Bacillus thuringiensis toxin resistance mechanisms among Lepidoptera: progress on genomic approaches to uncover causal mutations in the European corn borer, Ostrinia nubilalis

Brad S. Coates ${ }^{\mathrm{a}^{*}}$

${ }^{a} U S D A-A R S$, Corn Insects \& Crop Genetics Research Unit, Ames, IA, 50011.

*Corresponding Author

Brad S. Coates, Ph.D.

Research Geneticist

USDA-ARS, CICGRU

113 Genetics Laboratory

Iowa State University

Pammel Drive

Ames, IA 50011

Tel: 515-294-0668

Fax: 515-294-2426

brad.coates@ars.usda.gov 


\begin{abstract}
Transgenic plants that express Bacillus thuringiensis (Bt) crystal (Cry) protein toxins (Bt crops) effectively control feeding by the European corn borer, Ostrinia nubilalis, although documented resistance evolution among a number of species in both the laboratory and field has heightened concerns about the durability of this technology. Research has provided major insights into the mutations that alter Bt toxin binding receptor structure and function within the midgut of Lepidoptera that directly impacts the efficacy of Bt toxins, and potentially leads to the evolution of resistance to Bt crops in the field. In this manuscript we provide an overview of available data on the identification of genes involved in high levels of resistance to Cry toxins, with emphasis on resistance described for $O$. nubilalis as the main target of Bt corn.
\end{abstract}

\title{
Introduction
}

Transgenic Bt crops were first commercialized in 1996 with the approval of Cry1 Abexpressing Bt maize hybrids for the control of the European corn borer, Ostrinia nubilalis [1], and were followed by additional transgenic maize hybrids that express both Cry1 Ab and Cry $1 \mathrm{~F}$ toxins [2]. This introduction of Bt maize marked the start of a quintessential shift in the pest status of $O$. nubilalis in the United States, which prior to that time, was the most damaging maize pest in the United States [3]. Widespread adoption of Bt hybrids among producers [4,5] was credited for stark reductions in both the $O$. nubilalis population size and level of associated crop damage [6]. In addition, Bt maize also revolutionized how $O$. nubilalis and other pest insect populations are managed, in that insect resistance management (IRM) strategies became an essential component for technology stewardship aimed to delay the onset of functional resistance [7]. Current IRM tactics are based on the high-dose/refuge (HDR) strategy $[8,9,10]$ that has three basic assumptions; 1) resistance alleles within insect populations are rare and recessive, 2) transgenic toxins are expressed at a dose sufficient to render heterozygotes functionally susceptible, and 3) refuges of non-Bt maize grown near or blended within Bt maize fields are capable of producing an excess of homozygous susceptible individuals that will mate at random with any rare homozygous resistant individuals. Cry1 Ab susceptibility has been retained among O. nubilalis populations for nearly 20 years after the introduction of the Bt maize varieties in the United States, and may be a testament to the successful implementation of the HDR strategy $[6,11,12]$. Field damage by $O$. nubilalis has not been reported despite estimates of resistance allele frequencies exceeding modeling thresholds, which would otherwise suggest compromised durability $\left[13^{*}\right]$. These low observed Cry $1 \mathrm{~F}$ resistance allele frequencies may not be surprising considering effective population suppression provided by Cry1 Ab [6] and the fitness costs associated with Cry1F resistance [14] (Explanations of fitness costs in relation to Bt resistance found in $[15,16,17])$.

In contrast to $O$. nubilalis, functional resistance defined as the temporal reduction in susceptibility in an insect population after exposure to toxins under relevant field conditions $[18,19]$, has been documented among species of Lepidoptera that feed on Bt maize. These include the African stem borer, Busseola fusca, resistant to Cry1 Ab-expressing Bt maize in South Africa [19], and fall armyworm, Spodoptera frugiperda, with high levels of resistance toward Cry $1 F$ transgenic maize in Puerto Rico [20,21] and Brazil [22]. Additionally, among the cotton pest species, Pectinophora gossypiella show high tolerance to transgenic Cry1 Ac cotton plants in the field [23] and Helicoverpa armigera and H. zea show a decreased susceptibility to 
Cry1Ac over time [24-27]. Instances of field-evolved resistance might suggest that the biology of all lepidopteran pest insects may not fit within the basic tenants of the HDR strategy nor abide by parameters used to model product durability [28]. Recent reconfiguration of evolutionary models suggest that, even when exposed to high toxin doses, lack of random mating or small increases in the dominance of resistance alleles can negatively affect success of the HDR strategy [29**]. Empirical evidence indeed demonstrates that field-evolved resistance traits are dominant or incompletely recessive in the case of H. armigera [26,30], H. zea [31], and B. fusca [32]. Furthermore, low-dose insecticidal exposures have been implicated in the rapid evolution of field resistance in a coleopteran maize pest, the western corn rootworm (Diabrotica virgifera virgifera) $[33,34]$.

It could be argued that despite a priori acknowledgement that resistance phenotypes were likely to develop following widespread adoption of Bt crops and implementation of IRM plans aimed to circumvent or delay the onset of resistance, that the HDR strategy has been a mixed bag of success. Although field-evolved Bt resistance has been rare in terms of number of species [4], the impact has been great due to the effects on large scale agricultural production. The occurrence of resistance might suggest that our biological, ecological, or genetic data are insufficient for the design of long-term sustainable IRM plans [28,35**], or potentially to maintain the durability of certain crop protection technologies in the short-term [36]. In many causes, Bt technologies have been compromised due to insufficient knowledge of the complex interactions among genetic, biological and ecological factors that affect the rate at which resistant phenotypes develop [37]. The remainder of this review will focus on the molecular genetic basis of Bt toxin resistance among Lepidoptera, and provides a brief summary of current knowledge and a synthesis of genomic complexities governing the control of certain resistance traits that may constitute future interests of the research community. The field of genomics may indeed provide data that could be helpful for developing more sustainable of IRM strategies.

\section{Receptor-mediated resistance}

Inroads have been made with regards to elucidating the molecular genetic mechanisms that confer Bt resistance to lepidopteran insects, which has stemmed from results of biochemical, genetic, reverse genetic, and genomic experiments. Note that due to space limitations Bt mode of action will not be presented, but readers are directed to several reviews on the topic $[38,39,40]$. Additionally, descriptions of many methods described herein are presented by [41].

Aminopeptidase N (APN) proteins were initially identified as candidate resistance genes due to in vitro ability to bind Cry1 A toxins [42,43], and later implicated in the Bt mode of action following transcript knockdown by RNA interference (RNAi) $[44,45,46]$. APN's function as a CrylAc receptor is dependent upon post-translational addition of $\mathrm{N}$-acetylgalactoseamine (GalNAc) [47,48], although GalNAc independent binding has also been demonstrated [49]. An ancestral tandem duplication generated up to eight APN orthologs within the lepidopteran lineage $[50,51,52]$, which was confirmed in $O$. nubilalis by genetic linkage and physical mapping of orthologs onto genomic inserts of the OnB1 BAC library [53,54**]. Furthermore, Crava et al. [55] demonstrated that Cry1 Ab specifically bound the product of the O. nubilalis apn 1 gene (Onapn 1 ), whereas Cry1Fa toxin bound to Onapn3a and Onapn8 proteins. More importantly, resistance to Cry toxins was associated with reduced levels of the aminopeptidase N1 (apn1) transcript among S. exigua [56], Diatrea saccharalis [45], Trichoplusia ni [57**], 
and $O$. nubilalis [54**], and structural mutations in H. armigera apn 1 [58], which suggests involvement in $\mathrm{Bt}$ resistance evolution.

Alkaline phosphatases (ALPs) are hydrolytic enzymes that dephosphorylate a variety of molecules, and membrane-bound versions in the midgut of $M$. sexta and $H$. virescens bind Cry1Ac toxins in a GalNAc-dependent fashion $[59,60]$, which was similarly shown for the close relative to O. nubilalis, Asian corn borer, O. furnacalis [61]. Due to differences in temporal expression during larval development, $M$. sexta ALPs bind Cry1Ab prior to APNs [62], but ALP binding to Cryl $\mathrm{Ab}$ appears to be more crucial for toxicity in $M$. sexta compared to binding with Cry1Ac [63]. Furthermore, reduced expression of midgut ALP at the protein and mRNA levels are associated with increased resistance to Cryl toxins among $H$. armigera, $H$. virescens, and $S$. frugiperda [64**,65**,66,67]. The importance of ALP binding in the Cry1Ac toxin mode of action was demonstrated by incubation with an ALP toxin-binding fragment prior to ingestion by CrylAc resistant $H$. armigera, which resulted in reversion to a susceptible phenotype [67].

Cadherin belongs to a group of cell adhesion proteins, and the Manduca sexta ortholog, BT$\mathrm{R} 1$, was shown to bind Bt Cry1A toxins in vitro [68]. Cadherin from susceptible O. nubilalis similarly binds Cry1 Ab, Cry1 Ac and Cry1F toxins [69,70]. In vivo binding further demonstrated the functional role of cadherin in binding Cry1A toxins among O. nubilalis [71], B. mori [72] and $H$. virescens [73]. Structural mutations described within the cadherin gene were initially associated with CrylAc resistance among a laboratory strain of $H$. virescens [74] and allelic variants associated with CrylAc resistance from field-derived $P$. gossypiella [75] and $H$. armigera. Despite these prior associations, correlations between the segregation of cadherin alleles derived from $O$. nubilalis Cry $1 \mathrm{Ab}$ or Cry1F resistant parents and resistant progeny within $\mathrm{F}_{2}$ and backcross pedigree designs have not been correlated [35**,54**,76].

Lepidopteran ATP-binding cassette (ABC) proteins are membrane-bound transporters [77], and a premature stop codon mutation in the $\mathrm{ABCC} 2$ gene subfamily member $\mathrm{C} 2$ provided initial indication that it may function within the Cry1Ac resistance mechanism of $H$. virescens [78]. Analogous deletions and point mutations were subsequently linked to Cry1A toxin resistance among P. xylostella [79], Cry1 Ab resistance in B. mori [80], and Cry1Ac and Cry1Ca tolerance among $S$. exigua [81]. A locus containing the abcc2 gene was also implicated in an $O$. nubilalis Cry1F toxin resistance trait [35**] (see further discussion below). More recently, a truncation in the ABCA2 gene was genetically linked with Cry2A resistance in $H$. armigera and $H$. punctigera [82*], and expression of an ABCG subfamily member is reduced among CrylAc resistant $P$. xylostella larvae [83]. These studies established ABC transporters as an important player in both Bt toxin mode of action as well as a point at which mutations can confer resistance [84,85], even though the $\mathrm{ABC}$ transporter role in Bt toxin binding has not yet been established. Taken into context, identification of multiple mutations among independent genes leading to Bt resistance might suggest that species of Lepidoptera can attain some degree of tolerance in laboratory or field conditions by virtue of different evolutionary paths [15,86,87]. It remains to be seen if implication of $\mathrm{ABC}$ transporters in resistance of a large number of Lepidoptera will prove to be a universal underlying causal factor.

\section{Genetic control of receptor disregulation}

Resistance has evolved by means of reduced expression of Bt toxin receptors in the apn, alp and $a b c c$ gene families (see above), and a number of instances demonstrate that transcriptional control assorts independently of binding receptor geness such that one might deduce it to be 
under epistatic control (Box 1). Specifically, studies have highlighted the likely role of transregulatory mechanisms in the constitutive downregulation of transcription from genetic loci encoding APN1 [57**], APN1 and 3 [54**], and ABCC2 and 3 as well as ALP [65**]. Initial indications that gene regulation can be a factor in the evolution of Bt resistance among Lepidoptera came from the linkage between an endogenous transcriptional repression of apn 1 and upregulation of apn6 with the Cry1Ac resistant T. ni strain GLEN-Cry1Ac-BCS [69]. Importantly, and in contrast to prior studies that only documented reduced transcript levels $[45,56]$, Tiewsiri et al. [57**] also demonstrated that the genetic control of Cry1 Ac resistance segregated independent of the T. ni apn 1 locus within backcross pedigrees. Analogously, a trait that results in the constitutive down-regulation of the Onapn 1 transcript and confers Cry $1 \mathrm{Ab}$ tolerance in the $O$. nubilalis $\mathrm{Cry} 1 \mathrm{Ab}^{\mathrm{R}}$ colony was mapped to two quantitative trait loci (QTL) with high-throughput single nucleotide polymorphism (SNP) markers [88], and confirmed that both QTL for Cry1 Ab resistance segregated independently of apn loci [66,88]. These data suggest that QTL for Cry1 Ab and Cry1Ac resistance may directly modulate the transcription at certain unlinked apn genes, which is hypothesized to occur through the control of a transregulatory mechanism. Although simple from a genetic standpoint, these studies profoundly affected the conceptual framework by which Bt resistance is thought to develop; mainly that resistance can develop by transcriptional disregulation involving gene-regulatory networks (Box 1).

Interestingly, the T. ni QTL for Cry1 Ac resistance that controls the down-regulation of apn 1 [57**] was mapped to the $a b c c 2$ locus [79]. Although any connection between $a b c c 2$ and the transcriptional control of apn 1 remains unknown, these results might suggest a convergence between involvement of the abcc 2 locus and trans-regulatory control of the apn 1 . Recent evidence from P. xylostella may shed light into this control mechanism. Specifically, Guo et al., $\left[65^{* *}\right]$ reported linkage between control of alp transcription and inheritance of a QTL positioned within the same genomic region as $a b c c 1,2$, and 3. Conservation of $a b c c 1,2$, and 3 mutations among resistant and susceptible strains led these researchers to suspect other genes within this genome interval may be the causal factor for CrylAc resistance. Successful use of RNAi to knockdown transcripts for the proximal mitogen-activate protein kinase 4 gene (mapk4) resulted in both upregulation of alp as well as $a b c c 2$ and 3, and conversely endogenous down-regulation of these same genes were associated with elevated mapk 4 expression among Cryl Ac resistant compared to susceptible $P$. xylostella larvae [65**]. These findings are significant in that a genetic factor at the $a b c c 2$ locus (e.g. mapk4) was shown to control transcription of yet a different Bt toxin receptor, in this case alp. Even more importantly, these results implicate MAPK4 as a factor in trans-regulatory control of genes encoding known Bt toxin resistance genes. Supporting evidence may have come from results from ultra-high density genotyping-bysequencing (GBS) marker-based QTL mapping that implicated a locus containing $a b c c 2$ with segregation of an incompletely recessive $O$. nubilalis Cry1Fa resistance trait. Specifically, GBS markers adjacent to a marker for the $O$. nubilalis abcc 2 gene were more tightly associated with the QTL, which was interpreted to suggest tjat either another $a b c c$ gene or other linked genetic factor may be controlling Cry $1 \mathrm{~F}$ resistance in O. nubilalis [35**]. Recent whole-transcriptome and RNA-seq-based gene expression analyses indicated significant reductions in alp and apn transcripts in the midgut of Cry1F resistant compared to susceptible $O$. nubilalis, but ABC transporter-encoding transcripts were not identified within this pool of differentially-expressed genes [89*]. It will be interesting to see if mapk4 has any involvement in controlling apn expression and concomitant CrylAc or CrylAb toxin resistance traits in T. ni or O. nubilalis. 
Such information will provide a means to unravel the genetic architecture that leads to $O$. nubilalis Cry1F resistance.

\section{Conclusions}

Field-evolved resistance to Bt toxins expressed by transgenic crop plants represents a threat to current insect pest management practices, as well as a challenge to sustainable production practices. Laboratory models have proven valuable for the investigation of traits conferring $\mathrm{Bt}$ toxin resistance among species of Lepidoptera, and progress of this research has been facilitated by advances in molecular genetic- and genomic-level analyses [36]. Devising effective IRM plans will undoubtedly require additional investigations into the genomic architecture of resistance, as well as the myriad of complex biological and ecological interactions of the insect that modulate the function of this genetic architecture.

\section{Acknowledgements}

This work was a joint contribution from the United States Department of Agriculture (USDA), Agricultural Research Service (ARS) (CRIS Project 3625-22000-017-00), and the Iowa Agriculture and Home Economics Experiment Station, Ames, IA (Project 3543). Mention of trade names or commercial products in this publication is solely for the purpose of providing specific information and does not imply recommendation or endorsement by the for its use. USDA is an equal opportunity provider and employer.

\section{Box 1: Contributions of gene regulation in the evolution of Bt resistance}

Structural mutations that cause gross alterations in the proteins encoded by Bt toxin receptors in the insect midgut, such as truncations and frameshifts, are relatively straightforward to discern in the context of potential changes in toxin-receptor interactions; especially in cases when known Bt toxin-binding domains are altered or eliminated from the mature proteins. Similarly, the downregulation of transcript levels are surmised to result in concomitant reductions in protein levels, which for example would decrease Bt receptor titers in the midgut and disrupt the normal toxin mode of action. In this latter case, the causal basis of transcriptional dysregulation can be manifested by way of either cis- or trans-acting mutations, which respectively involve changes in regulatory elements on the same DNA strand in proximity to the gene coding sequence and those that can act by means of a diffusible factor encoded at a different genetic locus (Fig. 1).

Interestingly, in three instances wherein mutations in genes encoding trans-regulatory factors have been implicated in the Bt toxin resistance mechanisms that result from the downregulation of aminopeptidase $\mathrm{N}$, alkaline phosphatase, and ABCC transporter genes $\left[54^{* *}, 57^{* *}, 65^{* *}\right]$, and in all instances these mutations affected the quantitative expression of transcripts from two or more genes involved in mechanisms of $\mathrm{Bt}$ toxin resistance. In the case of T. $n i\left[57^{* *}\right]$ and $O$. nubilalis [54**], trans-regulatory mutations affect transcription from related members of midgut-expressed aminopeptidase $\mathrm{N}$ gene family, which may have retained a degree of coordinated control due to probable duplication from an ancestral copy. For O. nubilalis a trans-regulatory mutation appears to result from the combined effect of two independent QTL which may coordinate the down-regulation of apn 1 and apn 3 transcripts, although it remains unknown if these two factors act independently on the two separate genes or contribute 
additively. It remains unclear if this $O$. nubilalis dysregulation of apn 1 and apn3 results from an analogous trans-acting factor controlling apn 1 expression in $T$. $n i$ that was linked to the $a b c c 2$ locus [79], but considering the dissimilarities between apn 3 expression it is conceivable that the trans-acting factors in $O$. nubilalis could result from mutations at another points in the aminopeptidase $\mathrm{N}$ gene regulatory pathway.

In contrast, $P$. xylostella appears to have a single genome region (QTL) that has pleiotrophic effects on the transcription of ABC transporter and alkaline phosphatase [65**]; that is, changes in mapk 4 were shown to affect the expression of two seemingly unrelated genes. The connection between mapk 4 and the regulatory pathways of $\mathrm{Bt}$ toxin resistance genes remains unknown but could involve indirect modulation of individual control switches for the two gene families or connection within a larger yet undescribed signal transduction cascade.

Transcriptome-wide analyses of gene expression, such as the application of RNA-seq, hold the promise to help elucidate systemic changes in gene expression that are associated with these gene regulatory changes. Regardless, a small number of changes in gene regulatory cascades can result in a dramatic downstream effects. For instance, despite the introgression of an O. nubilalis Cry $1 \mathrm{~F}$ toxin resistance trait into a genetic background common to susceptible controls, several thousand transcripts showed significant quantitative changes between resistant and control larvae [89*]. This highlights the complications still presented for such genomic-wide studies, which may be inherent to the global changes invoked by mutations a few genes that regulate entire pathways. A greater understanding of the interconnectedness of gene regulatory pathways may be needed in order to fully appreciate the complex system-wide changes observed between resistant and susceptible phenotypes, and moreover to fully grasp the role gene-gene interactions may play in the evolution of Bt resistance among species of Lepidoptera. 
Figure 1: Differences between cis- and trans-regulatory controls involved in the alteration of gene transcription. A) In the wildtype situation, promoter sequences facilitate binding of one or more transcription factors (TF) and support synthesis of nascent transcripts, whereas mutant situations have incurred mutations in upstream promoter sequence which prevent TF binding even when the TF is present. B) Normal transcription can be interrupted when mutations occur at positions upstream within the gene regulatory network which either cause the diffusible TF to be non-functional or fail to be produced.

\section{A) cis-regulation}

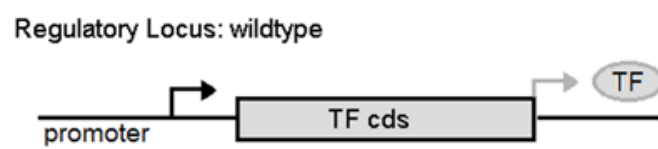

Regulatory Locus: wildtype

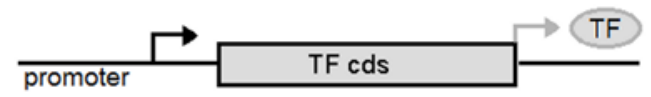

B) trans-acting factors

Regulatory Locus: wildtype

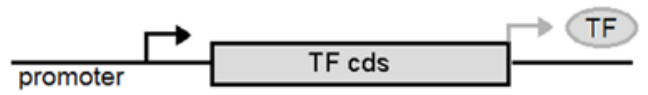

Regulatory Locus: mutant

promoter site mutation / protein truncation or substitution mutation

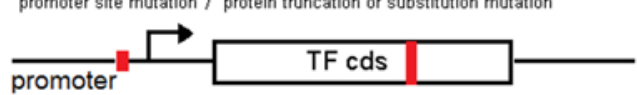

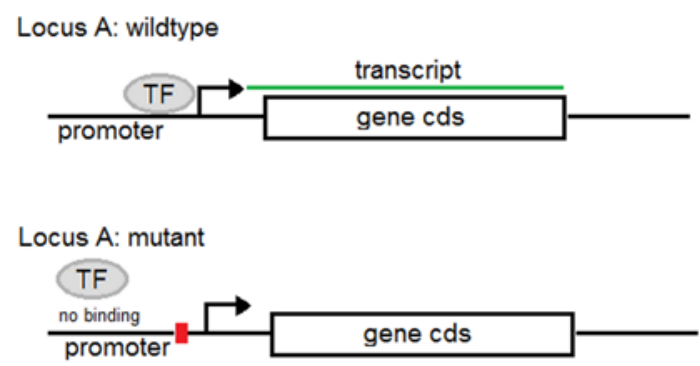

Locus A: wildtype

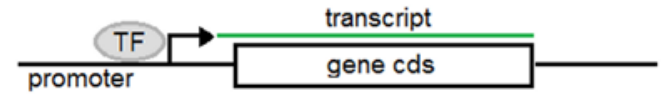

Locus A: wildtype

transcriptome factor absent/nonfunctional

promoter 
References

1. United States Environmental Protection Agency, Washington, DC, USA. Biopesticides registration action document - Bacillus thuringiensis plantincorporated protectants. E: Benefits assessment. 2001. Available at http://www.epa.gov/oppbppd1/biopesticides/pips/bt brad2/5-benefits.pdf.

2. United States Environmental Protection Agency, Washington, DC, USA. Biopesticides registration action document - Cry1Ab and Cry1F Bacillus thuringiensis $(\mathrm{Bt})$ corn plant-incorporated protectants. 2010. Available at http://www3.epa.gov/pesticides/chem search/reg actions/pip/cry1f-cry1abbrad.pdf

3. Mason CE, Rice ME, Calvin DD, Van Duyn JW, Showers WB, Hutchison WD, Witkowski JF, Higgins RA, Onstad DW, Dively GP: European corn borer: Ecology and Management Bulletin. NC-327, 1995. Iowa State University Press.

4. Tabashnik BE, Brévault $T$, Carrière $Y$ : Insect resistance to Bt crops: lessons from the first billion acres. Nat. Biotechnol. 2013, 31:510-521.

5. James C. Global Status of commercialized biotech/GM crops: 2014. International Service for the Acquisition of Agri-biotech Applications ISAAA Brief 20143, No. 49.

6. Hutchison WD, Burkness EC, Mitchell PD, Moon RD, Leslie TW, Fleischer SJ, Abrahamson M, Hamilton KL, Steffey KL, Gray ME, Hellmich RL, Kaster V, Hunt TE, Wright RJ, Pecinovsky KT, Rabaey TL, Flood BR, Raun ES: Areawide suppression of European corn borer with $\mathrm{Bt}$ maize reaps savings to non-Bt maize growers. Science 2010, 330:222-225.

7. Hellmich RL, Albajes R, Bergvinson D, Prasifka JR, Wang ZY, Weiss MJ: The present and future role of insect-resistant genetically modified maize in IPM, In: Integration of Insect-Resistant Genetically Modified Crops within IPM Programs, Edited by Romeis J Springer; 2008:119-158.

8. Alstad DA, Andow DA: Managing the evolution of insect resistance to transgenic plants. Science 1995, 268:1894-1896.

9. Gould F: Sustainability of transgenic insecticidal cultivars: integrating pest genetics and ecology. J. Econ. Entomol. 1998, 88:1545-1559.

10. Tabashnik BE, Van Rensburg JBJ., Carrière Y: Field-evolved insect resistance to Bt crops: definition, theory, and data. J. Econ. Entomol. 2009, 102:20112025. 
11. Siegfried BD, Hellmich RL: Understanding successful resistance management: The European corn borer and Bt corn in the United States. Special Issue GM Crops and Foods 2012, 3:184-193.

12. Huang F, Andow DA, Buschman LL: Success of the high - dose/refuge resistance management strategy after 15 years of Bt crop use in North America. Entomol. Exp. et Appl. 2011, 140:1-16.

13. * Siegfried BD, Rangasamy M, Wang H, Spencer T, Haridas CV, Tenhumberg B, Sumerford DV, Storer NP: Estimating the frequency of Cry1F resistance in field populations of the European corn borer (Lepidoptera: Crambidae). Pest. Manage. Sci. 2014, 70:725-733. Performed laboratory bioassays within a long-term field screening program aimed to monitor the frequency of Cry1F resistance alleles in Ostrinia nubilalis populations. This study demonstrated that allele frequencies are at levels that exceed minimum modeling thresholds that could suggest the durability of this Bt toxin would be compromised, but no fieldresistance has been observed.

14. Petzold-Maxwell JL, Siegfried BD, Hellmich RL, Abel CA, Coates BS, Spencer TA, Gassmann AJ: Effect of maize line on larval fitness costs of Cry1F resistance in the European corn borer (Lepidoptera: Crambidae). J. Econ. Entomol. 2014, 107:764-772.

15. Carrière $Y$, Tabashnik BE: Reversing insect adaptation to transgenic insecticidal plants. Proc. R. Soc. Lon. B Biol. Sci. 2001, 268:1475-1480.

16. Pittendrigh BR, Gaffney PJ, Huessing JE, Onstad DW, Rouch TR, Murdock LL: Active refuges can inhibit the evolution of resistance in insects towards transgenic insect-resistance plants. J. Theor. Biol. 2014, 231:461-474.

17. Gassmann AJ, Carrière $Y$, Tabashnik BE: Fitness costs of insect resistance to Bacillus thuringiensis. Ann. Rev. Entomol. 2009, 54:147-163.

18. National Research Council: Pesticide resistance: strategies and tactics for management. National Academy Press; 1986.

19. Van Rensburg JBJ: First field report of field resistance by the stem borer, Busseola fusca (Fuller) to transgenic maize. S. Afr. J. Plant. Soil. 2007, 24:147-151.

20. Matten RS, Head GP, Maclntoch SC: How government regulation can help or hinder the integration of Bt crops within IPM programs. In Integration of Insect Resistant Genetically Modified Crops with IPM Programs. Edited by Romeis J, Shelton AM, Kennedy GG. Springer Science Business Media B. V.: New York, USA, 2008:27-39. 
21. Storer NP, Babcock JM, Schlenz M, Meade T, Thompson GD, Bing JW, Huckaba RM: Discovery and characterization of field resistance to $B t$ maize: Spodoptera frugiperda (Lepidoptera: Noctuidae) in Puerto Rico. J. Econ. Entomol. 2010, 103:1031-1038.

22. Farias JR, Andow DA, Horiskoshi RJ, Sorgatto RJ, Fresia PF, Santos AC, Omoto C: Field-evolved resistance to Cry1F maize by Spodoptera frugiperda (Lepidoptera: Noctuidae) in Brazil. Crop Prot. 2014, 64:150-158.

23. Dhurua S, Gujar GT: Field-evolved resistance to Bt toxin Cry1Ac in the pink bollworm, Pectinophora gossypiella (Saunders) (Lepidoptera: Gelechiidae), from India. Pest. Manag. Sci. 2011, 67:898-903.

24. Gunning RV, Dang HT, Kemp FC, Nicholson IC, Moores GD: New resistance mechanism in Helicoverpa armigera threatens transgenic crops expressing Bacillus thuringiensis Cry1Ac toxin. Appl. Environl. Microbiol. 2005, 71:25582563.

25. Tabashnik BE, Carrière Y: Field-evolved resistance to Bt cotton: Bollworm in the U.S. and pink bollworm in India. Southwestern Entomol. 2010, 35:417424.

26. Zhang $\mathrm{H}$, Tian $\mathrm{W}$, Zhao J, Jin L, Yang J, Liu C, Yang Y, Wu S, Wu K, Cui J, Tabashnik BE, Wu Y: Diverse genetic basis of field-evolved resistance to Bt cotton in cotton bollworm from China. Proc. Natl. Acad. Sci. USA 2011, 109:10275-10280.

27. Alvi AHK, Sayyed AH, Naeem M, Ali M: Field evolved resistance in Helicoverpa armigera (Lepidoptera: Noctuidae) to Bacillus thuringiensis toxin Cry1Ac in Pakistan. PLOS ONE 2012, 7:e47309.

28. Gould F: Potential and problems with high-dose strategies for pesticidal engineered crops. Biocontrol Sci. Technol. 1994, 4:451-461.

29. ** Campagne P, Smouse PE, Pasquet R, Silvain JF, Le Ru B, Van den Berg J: Impact of violated high-dose refuge assumptions on evolution of Btresistance. Evol. Appl. 2016, doi: 10.1111/eva.12355. Authors revised standard modeling parameters to demonstrate that even mild departures from random mating and/or changes in dominance away from strictly recessive inheritance among resistance alleles can hasten the evolution of field resistance. Results are congruent with biological parameters that may have led to field-evolved resistance among Lepidopteran insects. 
30. Jin L, Wei Y, Zhang L, Yang Y, Tabashnik BE, Wu Y: Dominant resistance to $\mathrm{Bt}$ cotton and minor cross-resistance to $\mathrm{Bt}$ toxin Cry2Ab in cotton bollworm from China. Evol. Appl. 2013, 6:1222-1235.

31. Brévault T, Heuberger S, Zhang M, Ellers-Kirk C, Ni X, Masson L, Li X, Tabashnik BE, Carrière Y: Potential shortfall of pyramided transgenic cotton for insect resistance management. Proc. Natl. Acad. Sci. USA 2013, 110:5806-5811.

32. Campagne $\mathrm{P}$, Kruger M, Pasquet R, Le Ru B, Van den Berg J: Dominant inheritance of field-evolved resistance to Bt corn in Busseola fusca. PLOS ONE 2013, 8:e69675.

33. Gassmann AJ, Petzold-Maxwell JL, Keweshan RS, Dunbar MW: Field-evolved resistance to Bt maize by western corn rootworm. PLOS ONE 2011, 6:1-7.

34. Gassmann AJ, Petzold-Maxwell JL, Clifton EH, Dunbar MW, Hoffmann AM, Ingber DA, Keweshan RS: Field-evolved resistance by western corn rootworm to multiple Bacillus thuringiensis toxins in transgenic maize. Proc. Natl. Acad. Sci. USA 2014, 111:5141-5146.

35. ** Coates BS, Siegfried BD: Linkage of an ABC transporter to a single QTL that controls Ostrinia nubilalis larval resistance to the Bacillus thuringiensis Cry1Fa toxin. Insect Biochem. Mol. Biol. 2015, 63:86-96. Identified a large number of single nucleotide polymorphisms (SNPs) using a genotyping by sequencing approach, and performed fine mapping in Ostrinia nubilalis. High SNP marker density, including one within the abcc2 gene, identified the genome region containing the abcc2 gene as being linked to the QTL for Cry1F resistance, and identified markers more closely linked to the QTL compared to abcc2, suggesting that other locus may be the causal genetic factor.

36. Coates BS, Poelchau M, Childers C, Evans JD, Handler A, Guerrero F, Skoda S, Hopper K, Wintermantel WM, Ling KS, Hunter WB, Oppert B, Perez de Leon B, Hackett K., Shoemaker D. Arthropod genomics research in the United States Department of Agriculture-Agricultural Research Service: Current impacts and future prospects. Trends Entomol. 2015, 14:1-27.

37. Tabashnik BE, Carrière $Y$, Soberón J, Gao A, Bravo A: Successes and failures of transgenic Bt crops: global patterns of field-evolved resistance. In $B t$ resistance: characterization and strategies for GM crops producing Bacillus thuringiensis toxins. Edited by Soberón M, Gao Y, \& Bravo A. CABI; 1-14. 
38. Bravo A, Gill SS, Soberón M: Mode of action of Bacillus thuringiensis Cry1 and Cyt toxins and their potential for insect control. Toxicon 2007, 49:423435.

39. Jurat-Fuentes JL, Jackson TA: Bacterial entomopathogens. In Insect Pathology, $2^{\text {nd }}$ Edition. Edited by Vega FE, Laya HK. Elsevier; 265-349.

40. Pardo-Lopez L, Soberón M, Bravo A: Bacillus thuringiensis insecticidal three domain Cry toxins: mode of action, insect resistance and consequences for crop protection. FEMS Microbiol. Rev. 2013, 37:3-22.

41. Poelchau M, Coates BS, Childers C, Shoemaker D. Agricultural applications of insect ecological genomics. Curr. Opin. Insect Sci. 2016, 13:61-69.

42. Knight PJ, Knowles BH, Ellar DJ: Molecular cloning of an insect aminopeptidase $\mathbf{N}$ that serves as a receptor for Bacillus thuringiensis CrylA(c) toxin. J. Biol. Chem. 1995, 270:17765-17770.

43. Knight PJK, Knowles BH, Ellar DJ: The receptor for Bacillus thuringiensis CryIA(c) delta-endotoxin in the brush border membrane is aminopeptidase N. Mol. Microbiol. 1994, 11:429-436.

44. Rajagopal R, Sivakumar S, Agrawal N, Malhotra P, Bhatnagar RK: Silencing of midgut aminopeptidase $\mathbf{N}$ of Spodoptera litura by double-stranded RNA establishes it role as Bacillus thuringiensis toxin receptor. J. Biol. Chem. 2002, 277:46849-46851.

45. Yang Y, Zhu YC, Ottea J, Husseneder C, Leonard BR, Abel C, Huang F: Molecular characterization and RNA interference of three midgut aminopeptidase $\mathbf{N}$ isozymes from Bacillus thuringiensis-susceptible and resistance sugarcane borer, Diatrea saccharalis. Insect Biochem. Mol. Biol. 2010, 40:592-603.

46. Sivakumar S, Rajagopal R, Venkatesh GR, Srivastava A, Bhatnagar RK: Knockdown of aminopeptidase-N from Helicoverpa armigera larvae and in infected Sf21 cells by RNA interference reveals its functional interaction with Bacillus thuringiensis insecticidal protein Cry1Ac. J. Biol. Chem. 2007, 282:7312-7319.

47. Gill S, Cowles EA, Francis V: Identification, isolation, and cloning of a Bacillus thuringiensis CrylAc toxin-binding protein from the midgut of the lepidopteran insect Heliothis virescens. J. Biol. Chem. 1995, 270:2727727282. 
48. Luo K, Sangadala S, Masson L, Mazza A, Brousseau R, Adang MJ: The Heliothis virescens 170-kDa aminopeptidase functions as 'Receptor $A$ ' by mediating specific Bacillus thuringiensis Cry1A $\delta$-endotoxin binding and pore formation. Insect Biochem. Mol. Biol. 1997, 27:735-743.

49. Banks DJ, Jurat-Fuentes JL, Dean DH, Adang MJ: Bacillus thuringiensis Cry1Ac and Cry1Fa delta-endotoxin binding to a novel $110 \mathrm{kDa}$ aminopeptidase in Heliothis virescens is not $\mathbf{N}$-acetylgalactosamine mediated. Insect Biochem. Mol. Biol. 2001, 31:909-918.

50. Chang WX, Gahan LJ, Tabashnik BE, Heckel DG: A new aminopeptidase from diamondback moth provides evidence for a gene duplication event in Lepidoptera. Insect Mol. Biol. 1999, 8:171-177.

51. Angelucci C, Barrett-Wilt GA, Hunt DF, Akhurst RJ, East PD, Gordon KHJ, Campbell PM: Diversity of aminopeptidases, derived from four lepidopteran gene duplications, and polycalins expressed in the midgut of Helicoverpa armigera: Identification of proteins binding the -endotoxin, Cry1Ac of Bacillus thuringiensis. Insect Biochem. Mol. Biol. 2008, 38:685696.

52. Crava C, Bel Y, Lee SF, Manachini B, Heckel DG, Escriche B: Study of the aminopeptidase $\mathbf{N}$ gene family in the lepidopterans Ostrinia nubilalis (Hübner) and Bombyx mori (L.): Sequences, mapping and expression. Insect Biochem. Mol. Biol. 2010, 40:506-515.

53. Coates BS, Sumerford DV, Hellmich RL, Lewis LC: Repetitive genomic elements in a European corn borer, Ostrinia nubilalis, bacterial artificial chromosome library were indicated by bacterial artificial chromosome end sequencing and development of sequence tag site markers: implications for lepidopteran genomic research. Genome 2009, 52:57-67.

54. ${ }^{* *}$ Coates BS, Sumerford DV, Siegfried BD, Hellmich RL, Abel CA: Unlinked genetic loci control the reduced transcription of aminopeptidase $\mathrm{N} 1$ and 3 in the European corn borer and determine tolerance to Bacillus thuringiensis Cry1Ab toxin. Insect Biochem. Mol. Biol. 2013, 43:1152-1160. Using high-throughput single nucleotide polymorphism markers and gene expression analyses, this study showed that Cry $1 \mathrm{Ab}$ resistance is attributed to a gene regulatory mutation. The trans-regulatory factors are positioned at two independently segregating QTL (one major and one minor) that control the expression of aminopeptidase $\mathrm{N} 1$ in Ostrinia nubilalis larvae.

55. Crava CM, Bel Y, Jakubowska AK, Ferré J, Escriche B: Midgut aminopeptidase $\mathbf{N}$ isoforms from Ostrinia nubilalis: activity characterization and differential 
binding to Cry1 $\mathrm{Ab}$ and Cry1Fa proteins from Bacillus thuringiensis. Insect Biochem. Mol. Biol. 2013, 43:924-935.

56. Herrero S, Gechev T, Bakker PL, Moar WJ, de Maagd RA: Bacillus thuringiensis Cry1Ca-resistant Spodoptera exigua lacks expression of one of four aminopeptidase N genes. BMC Genomics 2005, 6:96.

57. ** Tiewsiri K, Wang P: Differential alteration of two aminopeptidases $\mathbf{N}$ associated with resistance to Bacillus thuringiensis toxin Cry1 Ac in cabbage looper. Proc. Natl. Acad. Sci. USA 2011, 108:14037-14042.

Represents the first published study that demonstrated that mutations in gene regulatory pathways can modulate the expression of a Bt binding receptor in the midgut of lepidopteran insects. Results led to a fundamental change in the scope of the possible genetic mechanisms by which Bt resistance may evolve.

58. Zhang S, Cheng H, Gao Y, Wang G, Liang G, Wu K: Mutation of an aminopeptidase $\mathbf{N}$ gene is associated with Helicoverpa armigera resistance to Bacillus thuringiensis Cry1Ac toxin. Insect Biochem. Mol. Biol. 2009, 39:421-429.

59. McNall RJ, Adang MJ: Identification of novel Bacillus thuringiensis Cry1Ac binding proteins in Manduca sexta midgut through proteomic analysis. Insect Biochem. Mol. Biol. 2003, 33:999-1010.

60. Krishnamoorthy M, Jurat-Fuentes JL, McNall RJ, Andacht T, Adang MJ: Identification of novel Cry1Ac binding proteins in midgut membranes from Heliothis virescens using proteomic analyses. Insect Biochem. Mol. Biol. 2007, 37:189-201.

61. Jin T, Duan X Bravo A, Soberón M., Wang Z, He K: Identification of an alkaline phosphatase as a putative Cry1 Ac binding protein in Ostrinia furnacalis (Guenée). Pest. Biochem. Physiol. 2015, doi: 10.1016/j.pestpb.2015.12.008.

62. Arenas I, et al.: Role of alkaline phosphatase from Manduca sexta in the mechanism of action of Bacillus thuringiensis Cry1Ab toxin. J Biol. Chem. 2010, 285:12497-12503

63. Flores-Escobar B, Rodriguez-Magadan H, Bravo A, Soberón M, Gomez I: Differential role of Manduca sexta aminopeptidase-N and alkaline phosphatase in the mode of action of Cry1Aa, Cry1Ab, and Cry1Ac toxins from Bacillus thuringiensis. Appl. Environ. Microbiol. 2013, 79:4543-4550.

64. ** Jurat-Fuentes JL. Karumbaiah L, Jakka SR, Ning C, Liu C, Wu K, Jackson J, Gould F, Blanco C, Portilla M, Perera O, Adang M: Reduced levels of 
membrane-bound alkaline phosphatase are common to lepidopteran strains resistant to Cry toxins from Bacillus thuringiensis. PLOS ONE 2011, 6:e17606. Although midgut-expressed alkaline phosphatase was known to bind $\mathrm{Bt}$ toxin in vitro authors established that the endogenous suppression of this gene is associated with Bt resistance across several different species of Lepidoptera. Results established alkaline phosphatase down-regulation as a crucial and widespread mechanism by which Bt resistance may develop.

65. ** Guo Z, Kang S, Chen D, Wu Q, Wang S, Xie W, Zhu X, Baxter SW, Zhou X, Jurat-Fuentes $\mathrm{JL}$, Zhang Y: MAPK signaling pathway alters expression of midgut ALP and ABCC genes and causes resistance to Bacillus thuringiensis Cry1Ac toxin in diamondback moth. PLoS Genet. 2015, 14:e1005124. Authors showed that alkaline phosphatase and ABCC genes are coordinately downregulated among Cry1Ac resistant larvae. Genetic control of Cry1Ac resistance was linked to a genome region that encoded the abcc2 gene, but through comparison of gene sequences between resistant and susceptible individuals concluded $A B C C$ receptors were not the causal factor. Through genome re-annotation and reverse genetics by way of RNAi knockdown, suggested that a mitogen-activated protein kinase 4 gene (mapk4) directly controls the level of alkaline phosphatase and abcc2 genes.

66. Jakka SRK, Gong L, Hasler J, Banerjee R, Sheets JJ, Narva K, Blanco CA, Jurat-Fuentes JL: Field-evolved Mode 1 fall armyworm resistance to $\mathrm{Bt}$ corn associated with reduced Cry1Fa toxin binding and midgut alkaline phosphatase expression. Appl. Environ. Microbiol. 2015, doi:10.1128/AEM02871-15.

67. Chen W, Liu C, Xiao Y, Zhang D, Zhang Y, Li X, Tabashnik BE, Wu K: A toxinbinding alkaline phosphatase fragment synergizes Bt toxin Cry1Ac against susceptible and resistant Helicoverpa armigera. 2015, PLoS ONE 10:e0126288.

68. Vadlamudi RK, Weber E, Ji I, Ji TH, Bulla Jr LA: Cloning and expression of a receptor for an insecticidal toxin of Bacillus thuringiensis. J. Biol. Chem. 1995, 270:5490-5494.

69. Hua G, Masson L, Jurat-Fuentes JL, Schwab G, Adang MJ: Binding analyses of Bacillus thuringiensis Cry-endotoxins using brush border membrane vesicles of Ostrinia nubilalis. Appl. Environ. Microbiol. 2001, 67:872-879.

70. Tan SY, Cayabyab BF, Alcantara EP, Huang F, He K, Nickerson KW, Siegfried $\mathrm{BD}$ : Comparative binding of Cry1 $\mathrm{Ab}$ and Cry1F Bacillus thuringiensis toxins to brush border membrane proteins from Ostrinia nubilalis, Ostrinia 
furnacalis and Diatraea saccharalis (Lepidoptera: Crambidae) midgut tissue. J. Invert. Pathol. 2013, 114:234-240.

71. Flannagan RD, Yu CG, Mathis JP, Meyer TE, Shi X, Siqueira HA, Siegfried B: Identification, cloning and expression of a Cry1Ab cadherin receptor from European corn borer, Ostrinia nubilalis (Hubner) (Lepidoptera: Crambidae). Insect Biochem. Mol. Biol. 2005, 35:33-40.

72. Nagamatsu Y, Koike T, Sasaki K, Yoshimoto A, Furukawa Y: The cadherin-like protein is essential to specificity determination and cytotoxic action of the Bacillus thuringiensis insecticidal CryIAa toxin. FEBS Lett. 1999, 460:385390.

73. Jurat-Fuentes $\mathrm{JL}$, Adang MJ: The Heliothis virescens cadherin protein expressed in Drosophila $\mathbf{2}$ cells functions as a receptor for Bacillus thuringiensis Cry1A but not Cry1Fa toxins. Biochem. 2006, 45:9688-9695.

74. Gahan LJ, Gould F, Heckel DG: Identification of a gene associated with Bt resistance in Heliothis virescens. Science 2001, 293:857-860.

75. Morin S, Biggs RW, Sisteron MS, Shriver L, Ellers-Kirk C, Higginson D, Holley D, Gahan LJ, Heckel DG, Carrière Y, Dennehy TJ, Brown JK, Tabashnik BE: Three cadherin alleles associated with resistance to Bacillus thuringiensis in pink bollworm. Proc. Natl. Acad. Sci. USA 2003, 100:5004-5009.

76. Coates BS, Sumerford DV, Lewis LC: Segregation of Ostrinia nubilalis aminopeptidase 1 (APN1), cadherin, and bre5-like alleles from a Cry1Ab resistant colony are not associated with $F_{2}$ larval weights when fed on toxin-containing diet. J. Insect Sci. 2008, 8:21.

77. Heckel DG: Learning the ABCs of Bt: $A B C$ transporters and insect resistance to Bacillus thuringiensis provide clues to a crucial step in toxin mode of action. Pestic. Biochem. Physiol. 2012, 104:103-110.

78. Gahan LJ, Pauchet $Y$, Vogel H, Heckel DG: An ABC transporter mutation is correlated with insect resistance to Bacillus thuringiensis Cry1Ac toxin. PLoS Genet. 2010, 6:e1001248.

79. Baxter S, Zhao JZ, Gahan LJ, Shelton AM, Tabashnik BE, Heckel DG: Novel genetic basis of field-evolved resistance to Bt toxins in Plutella xylostella. Insect Mol. Biol. 2005, 14:327-334.

80. Atsumi S, Miyamoto K, Yamamoto K, Narukawa J, Kawai S, Sezutsu H, Kobayashi I, Uchino K, Tamura T, Mita K, Kadono-Okuda K, Wada S, Kanda K, 
Goldsmith MR, Noda H: Single amino acid mutation in an ATP-binding cassette transporter gene causes resistance to Bt toxin Cry1Ab in the silkworm, Bombyx mori. Proc. Natl. Acad. Sci. USA 2012, 109:E1591-E1598.

81. Park Y, González-Martínez RM, Navarro-Cerrillo G, Chakroun M, Kim Y, Ziarsolo $P$, Blanca J, Canizares J, Ferre J, Herrero S: ABCC transporters mediate insect resistance to multiple $\mathrm{Bt}$ toxins revealed by bulk segregant analysis. BMC Biol. 2014, 12:46.

82. * Tay WT, Mahon RJ, Heckel DG, Walsh TK, Downes S, James WJ, Lee SF, Reineke A, Williams AK, Gordon KHJ: Insect resistance to Bacillus thuringiensis toxin Cry2Ab is conferred by mutations in an $A B C$ transporter subfamily A protein. PLoS Genet. 2015,11:e1005534. In contrast to prior studies that implicated $A B C C 2$ as a factor that determines Cry1A resistance in Lepidoptera, this study represents the first that linked an $A B C$ transporter in the subfamily $A$ to a different class of $B t$ toxins, Cry2Ab. Results suggest that other $A B C$ transporter gene families may be involved in a broad range of $B t$ resistance mechanisms.

83. Guo Z, Kang S, Zhu Z, Xia J, Wu Q, Wang S, Xie W, Zhang Y: Down-regulation of a novel ABC transporter gene (Pxwhite) is associated with Cry1Ac resistance in the diamondback moth, Plutella xylostella (L.). Insect Biochem. Mol. Biol. 2015, 59:30-40.

84. Heckel DG: Roles of $A B C$ proteins in the mechanism and management of $\mathrm{Bt}$ resistance. Bt resistance: characterization and strategies for $\mathbf{G M}$ crops producing Bacillus thuringiensis toxins. In Bt resistance characterization and strategies for GM crops producing Bacillus thuringiensis toxins. Edited by Soberón M, Gao A, Bravo A. CABI; 2015, 98-106.

85. Tabashnik BE: ABCs of Insect Resistance to Bt. PLoS Genet. 2015, 11:e1005646.

86. Griffitts JS, Aroian RV: Many roads to resistance: how invertebrates adapt to Bt toxins. Bioessays 2005, 27:614-624.

87. Heckel DG, Gahan LJ, Baxter SW, Zhao JZ, Shelton AM, Gould F, Tabashnik $\mathrm{BE}$ : The diversity of $\mathrm{Bt}$ resistance genes in species of Lepidoptera. $J$ Invert. Pathol. 2007, 95:192-197.

88. Coates BS, Bayles DO, Wanner KW, Robertson HM, Hellmich RL, Sappington TW: The application and performance of single nucleotide polymorphism (SNP) markers for population genetic analyses of Lepidoptera. Front. Genet. 2011, 2:38. 
89. * Vellichirammal NN, Wang H, Eyun S, Moriyama EN, Coates BS, Miller NJ, Siegfried BD: Transcriptional analysis of susceptible and resistant corn borer strains and their response to Cry1F protoxin. BMC Genomics 2015, 16:558. A genomics approach was used to analyze the entire midgut transcriptome of Ostrinia nubilalis. Results showed that gene expression did not change among Cry $1 \mathrm{~F}$ resistant exposed to Cry1F toxin compared to those on control diet, indicating that cellular damage due to pore formation likely does not occur. Additionally, the study established that Cry1F resistant larvae have constitutive reductions in alkaline phosphatase and aminopeptidase $\mathrm{N}$ transcript levels. 